\section{$\underset{\substack{\text { hommes } \\ \text { \& migrations }}}{ }$}

\section{Hommes \& migrations}

Revue française de référence sur les dynamiques

migratoires

$1330 \mid 2020$

1973, l'année intense

\title{
Dominique Manotti, Marseille 73
}

Équinoxe/Les Arènes, Paris, 2020, 384 pages, $20 €$.

\section{Mogniss H. Abdallah}

\section{Q OpenEdition \\ 1 Journals}

\section{Édition électronique}

URL : https://journals.openedition.org/hommesmigrations/11652

DOI : 10.4000/hommesmigrations. 11652

ISSN : 2262-3353

\section{Éditeur}

Musée national de l'histoire de l'immigration

\section{Édition imprimée}

Date de publication : 17 juillet 2020

Pagination : 238

ISBN : 978-2-919040-51-3

ISSN : 1142-852X

\section{Référence électronique}

Mogniss H. Abdallah, « Dominique Manotti, Marseille 73 », Hommes \& migrations [En ligne], 1330 | 2020, mis en ligne le 01 juillet 2020, consulté le 05 janvier 2023. URL : http://journals.openedition.org/

hommesmigrations/11652; DOI : https://doi.org/10.4000/hommesmigrations. 11652 


\section{Livres}

\section{Marseille 73}

Dominique Manotti, Paris, Équinoxe/Les Arènes, 2020, 384 p., $20 €$

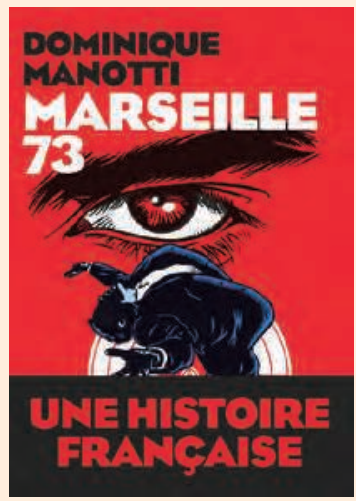

L'écriture de l'Histoire avec un grand $\mathrm{H}$ et roman policier, est-ce compatible? À suivre Dominique Manotti, on est invité à y souscrire. Cette auteure d'une douzaine de polars remarqués est agrégée d'histoire, une matière qu'elle a auparavant enseigné. Avec Marseille 73, elle nous entraîne sur le terrain de la vague de crimes racistes qui a endeuillé le Midi de la France lors de l'été 1973. Le prologue, factuel, commence par la journée du 12 juin 1973 à Grasse (Alpes-Maritimes) qui plante le décor: suite à un rassemblement de sans-papiers surtout Tunisiens - devant la mairie pour protester contre les circulaires Marcellin-Fontanet de 1972 (qui subordonnent le séjour des étrangers à un contrat de travail et à un logement décent), les CRS interviennent. S'ensuit une «chasse aux Arabes » menée par des habitants se réclamant d'un "comité de vigilance des commerçants et artisans », et d'organisations de rapatriés d'Algérie. La nuit précédente, des affiches «Halte à l'immigration sauvage » signées du groupe d'extrême-droite Ordre nouveau sont apparues. On parle dès lors de «ratonnades». Dans sa postface,
Marseille 73 dresse le bilan de cet année meurtrière: une quinzaine de morts, pour la plupart Algériens, dans la cité phocéenne, une cinquantaine dans la France entière. Seuls deux assassins seront identifiés, dont un policier qui mourra en prison d'une crise cardiaque. Toutes les autres procédures se concluront par des non-lieux ou des classements sans suite. Côté pouvoirs publics, c'est le déni. Le président Pompidou ira jusqu'à évoquer un «bruit inconsidéré » autour de ces affaires.

Dans le corps même de son intrigue policière, l'auteure prend délibérément une certaine liberté avec les faits, leur chronologie ou les noms pour installer ses personnages, dont le commissaire Daquin, chargé d'enquêter sur «l'Union des Français repliés d'Algérie (UFRA)» à Marseille, suite à des actions illégales de membres violents de ce regroupement à Toulon. La hantise ambiante: le spectre de l'Organisation de l'armée secrète (OAS), et l'infiltration dans différents services de police, eux-mêmes traversés de nombreux affrontements et rivalités.

Le 26 août 1973, survient le meurtre du traminot Emile Guerlache par un déséquilibré algérien. Émoi maximum. Le soir même de son enterrement, une équipée en voitures part «de l'autre côté de la frontière, à Marseille Nord», et tue un jeune de 16 ans, ici renommé Malek Khider. À rebrousse-poil de son institution, le commissaire Daquin va dès lors se focaliser sur cette affaire, rencontre les frères de la victime qui contribuent à faire aboutir l'enquête, bien qu'on tente de les salir par un coup monté les impliquant dans un projet imaginaire de hold-up armé. Le père, lui, a un sacré tempérament, tout le contraire du «travailleur immigré muet, noyé dans le chagrin», et tiendra tête au juge d'instruction au passé collabo. Dans la vraie vie, il s'agit sans doute de Lhadj Lounès et de sa famille, pour laquelle le Mouvement des travailleurs arabes (MTA) s'est beaucoup investi. Le roman relate ainsi la marche silencieuse qui accompagne la dépouille au ferry, l'arrêt de travail sur le chantier naval de La Ciotat, l'organisation de la grève générale contre le racisme le 3 septembre, puis la montée sur Paris le 14, l'expulsion du pasteur suisse Berthier Perregaux de la Cimade, ou encore la confection du Vrai Méridional, journal-tract pastichant le grand quotidien régional. De belles pages pleines d'empathie, au rythme soutenu. Dilemme: l'absence de repères pour délimiter réalité et fiction, mélangées. Aux lecteurs et aux chercheurs d'approfondir par eux-mêmes. Pour compléter la lecture de Marseille 73, on peut se replonger dans Les dossiers noirs du racisme dans le Midi de la France, paru au Seuil en 1976, ou dans La Race tue deux fois. Une histoire des crimes racistes en France (1970-2000), un ouvrage de Rachida Brahim à paraître aux éditions Syllepse.

Mogniss H. Abdallah 